\title{
Squamous Cell Carcinoma Metastatic to the Heart Mimicking ST- Elevation Myocardial Infarction
}

\author{
Jason Chen, MD \\ Thomas Jefferson University, jason.chen@jefferson.edu \\ Colin Craft, MD \\ Thomas Jefferson University Hospital, colin.craft@jefferson.edu \\ Andrew W. Panakos, MD \\ Thomas Jefferson University, andrew.panakos@jefferson.edu \\ Gregary D. Marhefka, MD, FACC, FACP \\ Thomas Jefferson University, Gregary.Marhefka@jefferson.edu
}

Follow this and additional works at: https://jdc.jefferson.edu/tmf

Part of the Cardiology Commons, and the Internal Medicine Commons

Let us know how access to this document benefits you

\section{Recommended Citation}

Chen, MD, Jason; Craft, MD, Colin; Panakos, MD, Andrew W.; and Marhefka, MD, FACC, FACP, Gregary D. (2016) "Squamous Cell Carcinoma Metastatic to the Heart Mimicking ST-Elevation Myocardial Infarction," The Medicine Forum: Vol. 17 , Article 3.

DOI: https://doi.org/10.29046/TMF.017.1.003

Available at: https://jdc.jefferson.edu/tmf/vol17/iss1/3

This Article is brought to you for free and open access by the Jefferson Digital Commons. The Jefferson Digital Commons is a service of Thomas Jefferson University's Center for Teaching and Learning (CTL). The Commons is a showcase for Jefferson books and journals, peer-reviewed scholarly publications, unique historical collections from the University archives, and teaching tools. The Jefferson Digital Commons allows researchers and interested readers anywhere in the world to learn about and keep up to date with Jefferson scholarship. This article has been accepted for inclusion in The Medicine Forum by an authorized administrator of the Jefferson Digital Commons. For more information, please contact: JeffersonDigitalCommons@jefferson.edu. 


\title{
Squamous Cell Carcinoma Metastatic to the Heart Mimicking ST-Elevation Myocardial Infarction
}

\author{
Jason Chen, MD, Colin Craft, MD, Andrew Panakos, MD, Gregary D. Marhefka, MD, FACC, FACP
}

\section{INTRODUCTION}

Heart disease remains the leading cause of mortality in the United States, accounting for about one quarter of all deaths in 2013. Acute ischemic heart disease is a major subpopulation of this group, and typically presents with characteristic electrocardiographic (EKG) changes. The most concerning of these findings are ST-elevations, as ST Elevation Myocardial Infarction (STEMI) typically indicates the need for emergent reperfusion therapy because 30-day mortality of untreated STEMI is approximately $10-15 \%$ versus $5 \%$ in treated cases $^{2}$. As a result, clinicians are taught to recognize the symptoms and signs of myocardial ischemia and STEMI in order to achieve timely reperfusion either via thrombolytic therapy within 30 minutes or percutaneous coronary intervention within 90 minutes.

However, ST-elevations may result from etiologies other than acute ischemia, and can be secondary to other acutely life-threatening pathologies or relatively benign, subacute causes. For example, ventricular aneurysms resulting from prior myocardial infarction and pericarditis can result in ST-elevation on EKG. Intracranial hemorrhage or stress (takotsubo) cardiomyopathy can also present with ST-elevations, theorized to be the result of increased catecholamines. Left ventricular hypertrophy, a sequela of poorly controlled hypertension, can also lead to J point elevations mimicking STEMI3.

Here we review a case of unusual ST-elevation in a patient with oropharyngeal squamous cell carcinoma metastatic to the heart.

\section{CASE PRESENTATION}

A 55 year old male with a history of hepatitis C cirrhosis, hypertension, and squamous cell carcinoma of the mouth status post resection and weekly cisplatin/ paclitaxel chemotherapy and postoperative radiation therapy to the neck, with known diffuse metastases, presented with confusion and generalized weakness. His initial physical exam was significant for hyperpigmentation of his neck and decreased breath sounds bilaterally. His laboratory values showed hypercalcemia with an ionized calcium of $7.4 \mathrm{mg} / \mathrm{dL}$ (normal $4.5-5.3 \mathrm{mg} / \mathrm{dL}$ ). Additionally, he was found to have troponin $T$ of $0.10 \mathrm{ng} /$ $\mathrm{mL}$ (normal $<0.01 \mathrm{ng} / \mathrm{mL}$ ) and EKG showed 1 to $5 \mathrm{~mm}$ ST-elevation in V2-V6 (Figure 1). Of note, an EKG done four days prior showed ST-elevation, though less pronounced (Figure 2). Chest x-ray showed bilateral lung nodules consistent with metastases and bilateral airspace disease (Figure 3). Urine drug screen was negative.

\section{DIFFERENTIAL DIAGNOSIS}

The differential diagnosis for ST-elevation includes STEMI, aortic dissection, pulmonary embolism, stress (takotsubo) cardiomyopathy, pericarditis with or without effusion, myocarditis, hypercalcemia, hyperkalemia, coronary vasospasm, coronary artery dissection, left ventricular aneurysm, left ventricular hypertrophy, the Brugada syndrome, left bundle branch block, early repolarization, early post-cardioversion, intracranial hemorrhage, and rarely, tumor invasion of the heart 3,4,5,6.

\section{OUTCOME}

Because of his hypercalcemia, the patient was administered aggressive intravenous (IV) hydration and IV bisphosphonates. Given the concern for STEMI, a transthoracic echocardiogram was performed immediately which showed a $2.4 \mathrm{~cm}$ mass involving the epicardium and myocardium of the left and right ventricular apices and an ejection fraction of $75 \%$ without segmental wall motion abnormalities (Figures 4 and 5). His serial troponin values decreased to $0.09 \mathrm{ng} / \mathrm{mL}$ and $0.08 \mathrm{ng} / \mathrm{mL}$ over the next twelve hours. Cardiology was consulted and deemed that given the patient's history, absence of specific cardiac symptoms, prior ST-changes, and echo findings, the EKG changes were likely due to metastatic disease rather than acute coronary syndrome. One suspected etiology of the ST changes was from his significant hypercalcemia. However, after resolution of his hypercalcemia, the ST elevations persisted on EKG. Interestingly, prior to the patient's diagnosis of metastatic disease, his EKG did not show these ST changes (Figure 6). Furthermore, the patient's ST elevations persisted after correction of his hypercalcemia. Further workup for his altered mental status revealed diffuse brain metastases and a sternal wound concerning for infection so he was started on broad spectrum antibiotics. Despite optimal medical therapy, he had worsening shortness of breath and hemodynamic instability. Given his poor prognosis, the family and health care providers agreed that a comfort care approach would be consistent with his wishes. He passed away two weeks after admission.

\section{DISCUSSION}

When evaluating for potential acute coronary syndrome in the presence of ST-elevation on electrocardiogram, myocardial ischemia should always be the first consideration, as a delay in providing revascularization can prove catastrophic. However, after acute coronary artery occlusion or coronary plaque rupture secondary to atherosclerotic disease have been ruled out, it is important to consider other causes for myocardial injury. Malignancy with metastatic involvement of the heart is a rare cause of ST-elevation? 


\section{The Medicine Forum, Vol. 17 [2016], Art. 3}

Though often clinically insignificant, the incidence of cardiac involvement in patients with known malignancy is estimated between $9.1 \%-25.0 \%$ based on current literature 8.9 . Nearly all varieties of malignancy can metastasize to the heart, the most common being primary lung cancer, primary breast cancer, hematologic malignancies, and malignant melanoma ${ }^{10}$. There are four primary pathways by which tumors can invade the heart: hematogenous spread, lymphatic spread, transvenous extension, and direct extension.

The location of neoplastic metastasis typically dictates the subsequent symptomatology. The most common clinical manifestations of tumors extending to the pericardium are pericarditis and pericardial effusions, which can be further complicated by cardiac tamponade. Malignant effusions may develop insidiously or rapidly, and the risk of tamponade development is always present regardless of the size of the effusion. In addition, small metastases to the pericardium have rarely been shown to cause constrictive pericarditis ${ }^{10}$.

The clinical picture that develops in the setting of pericardial involvement is distinctly different from that of epicardial, myocardial, or endocardial involvement. Case reports from the literature describe episodes of both atrial and ventricular arrhythmias, along with complete heart block due to invasion of the cardiac conduction system. Additionally, significant infiltration of metastatic disease into the coronary arteries, or extrinsic compression from metastases or tumor burden, can result in a clinical scenario mimicking acute coronary syndrome in regards to both patient symptoms and EKG changes 8.10 .

When a patient with a known malignancy presents with the new onset of cardiac symptoms in the absence of another clear diagnosis, it is paramount to consider and work up the possibility of metastatic disease. EKG findings in metastasis to the myocardium may reveal ST-elevations in contiguous leads that are persistent and not evolving and typically are not accompanied by ST-depression in reciprocal leads. Furthermore, EKG involvement of the pericardium may show signs of low voltage or electrical alternans, suggesting possible effusion or diffuse ST elevation suggesting pericarditis ${ }^{10}$. However, more definitive imaging is needed to complete a metastatic work up. Echocardiogram will reveal the presence of overt cardiac masses and also pericardial effusions and tamponade physiology, but it should only compose part of the work up. Cardiac computerized tomography (CT) would reveal tumor extension from proximal anatomic sites, and coronary CT would provide evaluation of coronary vasculature. On positron emission tomography (PET), metastases will often show increased metabolic activity. Of note, cardiac MRI provides the best tissue characterization of the myocardium and is often able to identify metastases missed on both cardiac CT and echocardiography ${ }^{12}$.

Management of these conditions depends on the clinical symptoms at presentation. Cardiac tamponade merits urgent intervention via placement of a pericardial drain and subsequent evaluation for local radiotherapy and possible chemotherapy to reduce the metastatic burden. The same is true for brady- or tachy-arrhythmias induced by cardiac metastasis, though symptoms can be mitigated by placement of a pacemaker or the use of anti-arrhythmic medication, respectively. If cardiac metastases are leading to coronary artery occlusion or compression causing ischemic symptoms, urgent surgical resection, radiation therapy, or coronary angiography should be considered.

\section{KEY POINTS}

- The differential for ST-elevation includes STEMI, stress cardiomyopathy, pericarditis, myocarditis, left ventricular aneurysm, coronary vasospasm, pulmonary embolism, the Brugada syndrome, left ventricular hypertrophy, left bundle branch block, early repolarization, hyperkalemia, and rarely, tumor invasion of the heart $33,5,6$.

- The clinical context, ST morphology and distribution, comparison with prior EKGs and echocardiogram can help distinguish between etiologies of ST-elevation.

- Patients with known or suspected metastatic disease who present with possible ischemic heart disease or rhythm disturbance should undergo a prompt cardiac workup beginning with EKG and echocardiography, with further imaging if clinical suspicion of cardiac involvement persists.

\section{REFERENCES}

1. Heron M. Deaths: Leading Causes for 2012. National Vital Statistics Reports. 2015;64(10):1-93

2. Cohen M, Boiangiu C, Abidi M. Therapy for ST-segment Elevation Myocardial Infarction Patients Who Present Late or are Ineligible for Reperfusion Therapy. J Am Coll Cardiol. 2010;55(18):1895-1906.

3. Wang K, Asinger R, Marriott H. ST-Segment Elevation in Conditions Other Than Acute Myocardial Infarction. The New England Journal of Medicine. 2003; 349:2128-35

4. Chandra S, Singh S, Nehra M, Agarwal D, Singh N. ST-segment elevation in non-atherosclerotic coronaries: a brief overview. International Journal of Emergency Medicine. 2011;6(2):129-139.

5. Gu YL, Svilaas T, van der Horst ICC, Zijlstra F. Conditions mimicking acute ST-segment elevation myocardial infarction in patients referred for primary percutaneous coronary intervention. Netherlands Heart Journal. 2008; 16(10):325-331

6. Hanna E, Glancy DL. ST-segment elevation: Differential diagnosis, caveats. Cleveland Clinic Journal of Medicine. 2015;82(6):373-384.

7. Gard J, Bader W, et al. Images in Cardiovascular Medicine: Uncommon Cause of ST Elevation. Circulation. 2011;123:e259-e261.

8. Reynen K, Kocheritz U, Strasser RH. Metastases to the heart. Annals of Oncology 2004:15:275-381.

9. Goldberg AD, Blankstein R, Padera RF. Tumors metastatic to the heart. Circulation. 2013:128(16):1790-1794.

10. Perazzolo Marra M, Thiene G, et al. Concealed metastatic lung carcinoma presenting as acute coronary syndrome with progressive conduction abnormalities. Circulation. 2012;125:e499-e502.

11. Bussani R, De-Giorgio F, Abbate A, Silvestri F. Cardiac metastases. J Clin Pathol. 2007:60:27-34

12. Bruce CJ. Cardiac tumours: diagnosis and management. Heart. 2011;97:151-160 


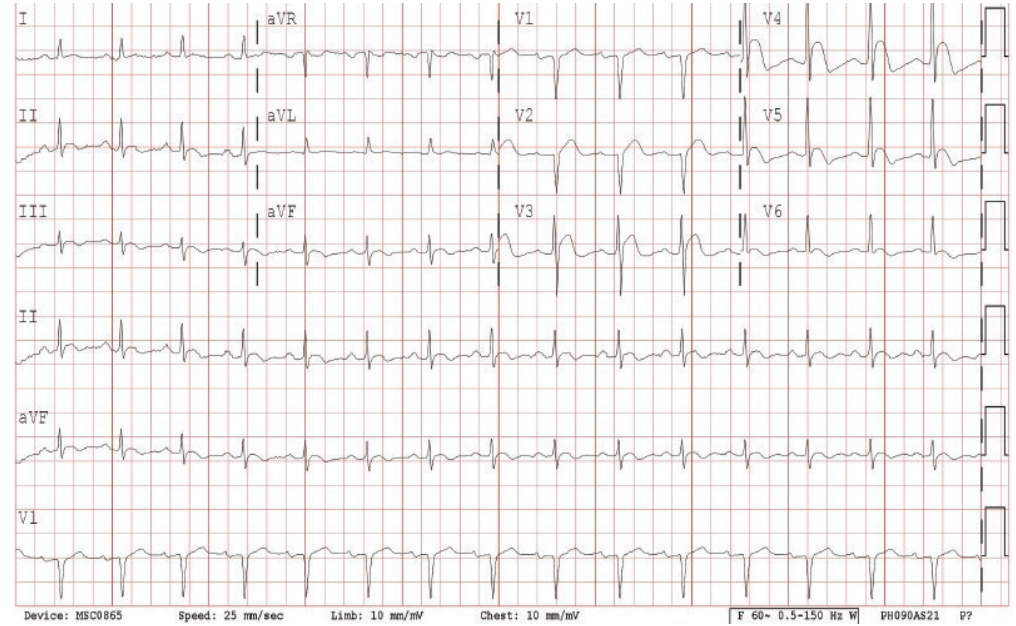

Figure 1. EKG from admission showing 1-5mm ST-elevations in leads V2-V6.

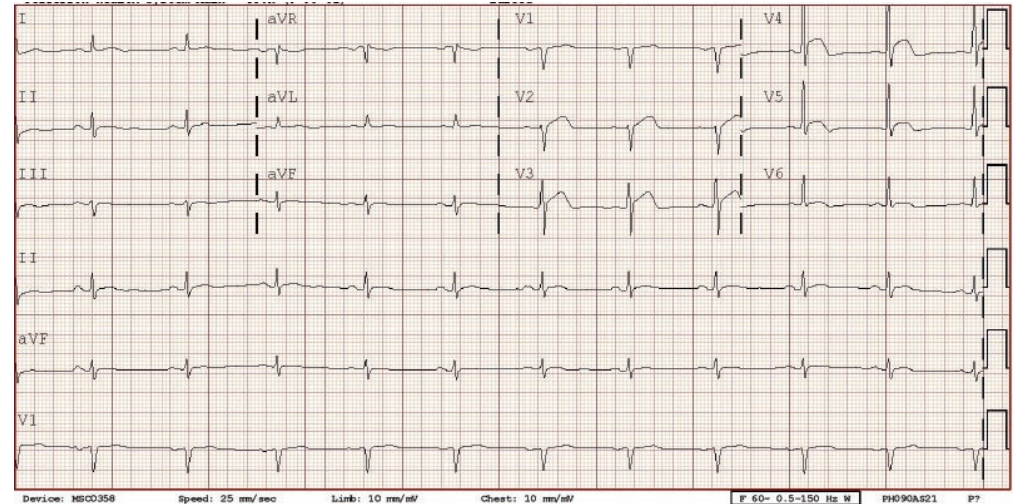

Figure 2. EKG four days prior to admission showing less prominent ST elevations in V2-V5, compared to admission to EKG.

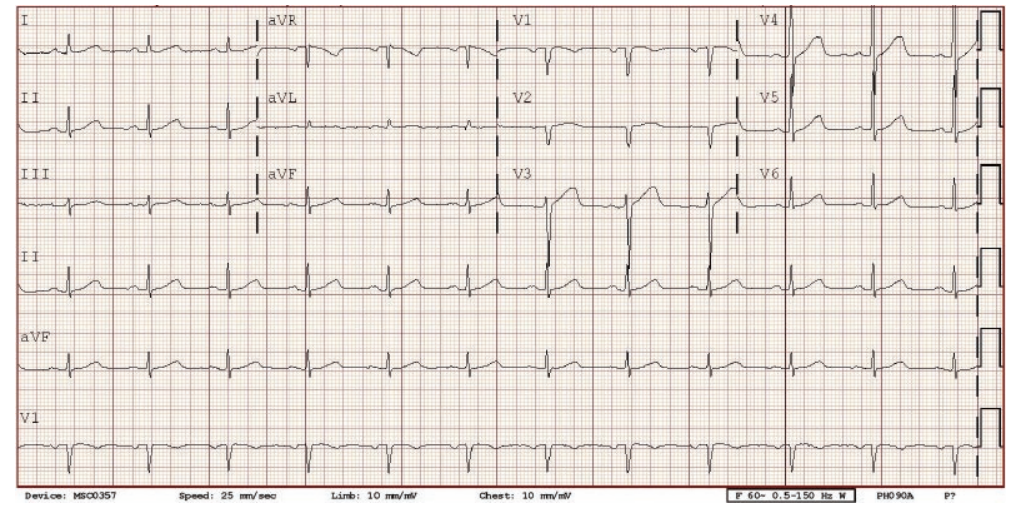

Figure 6. EKG from before patient developed metastatic disease showing no ST-elevations.

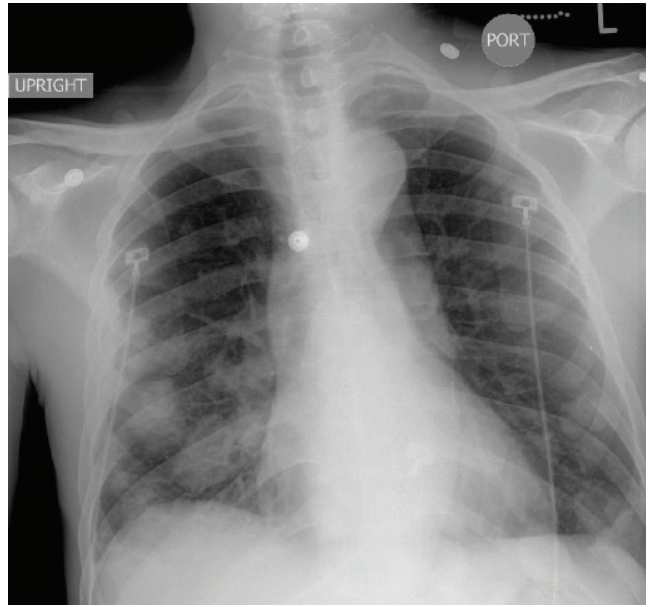

Figure 3. Single-view chest $x$-ray on admission showing multiple round masses within both lungs, predominantly in the lower lung fields. The largest measures approximately $4.6 \times 2.5 \mathrm{~cm}$ in the right base.

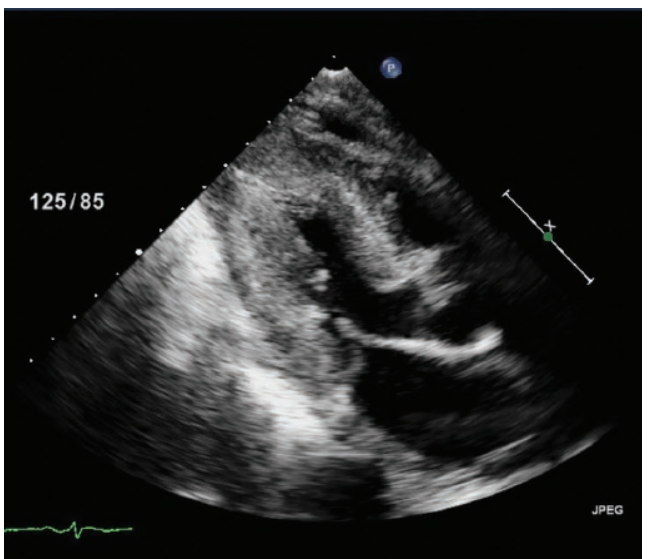

Figure 4. Echocardiogram showing $2.4 \mathrm{~cm}$ mass at left and right ventricular apex: parasternal long axis view.

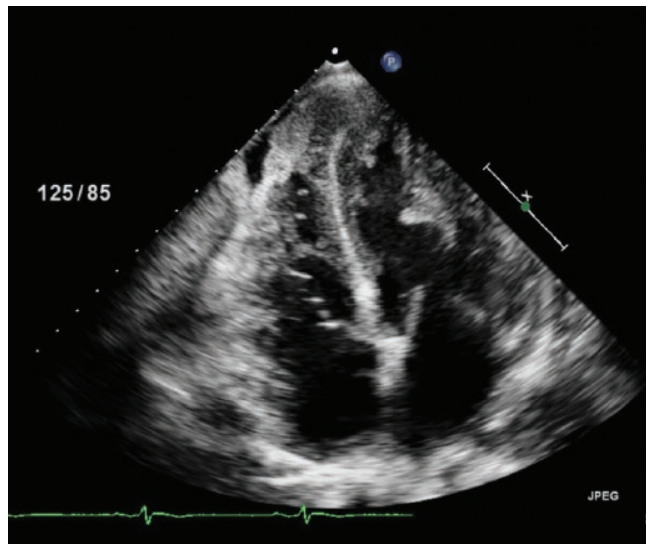

Figure 5. Echocardiogram showing $2.4 \mathrm{~cm}$ mass at left and right ventricular apex: apical four chamber view. 